\title{
Unsymmetrically substituted imidazolium salts: synthesis, characterization and antimicrobial activity
}

\author{
Esin Poyrazoğlu Çoban",*, Rukiye Fırıncı², Halil Biyik, Muhammet Emin Günay² \\ ${ }^{1}$ Department of Biological Sciences, Faculty of Arts and Sciences, Adnan Menderes University, Aydin, Turkey, ${ }^{2}$ Department of \\ Chemistry, Faculty of Arts and Sciences, Adnan Menderes University, Aydin, Turkey
}

\begin{abstract}
Unsymmetrically substituted imidazolium salts were synthesized and characterized using ${ }^{1} \mathrm{H}-\mathrm{NMR}$ and ${ }^{13} \mathrm{C}$-NMR. The antimicrobial activities of the salts were evaluated using the agar-well diffusion method against 14 bacteria and five yeasts. The minimal inhibitory concentrations (MIC) against seven bacteria and one yeast were also determined. Among the test compounds applied, 1, 2, 3, 6 and 11 showed activities against Micrococcus luteus ATCC 9341, Staphylococcus aureus ATCC 25923, Staphylococcus epidermidis ATCC 12228, Bacilllus cereus ATCC 11778, Bacillus subtilis ATCC 6633, Bacillus thuringiensis, Listeria monocytogenes ATCC 19112 and Candida trophicalis. However, compounds 1, 2 and 3 showed the highest antimicrobial activities against Micrococcus luteus ATCC 9341, Stapylococcus aureus ATCC 25923, Staphylococcus epidermidis ATCC 12228, Bacilllus cereus ATCC 11778 and Bacillus subtilis ATCC 6633 with inhibition zones of 14-20 mm. In addition, compound 6 have only demonstrated activities against Candida trophicalis while compounds 4, 5, 7, 8, 9, 10, 12, 13 and 14 had no effect on test microorganisms.
\end{abstract}

Uniterms: Imidazolium salts/characterization. $N$-heterocyclic carbenes. Imidazolium salts/antimicrobial activity. Imidazolium salts/Minimum inhibitory concentration.

\section{INTRODUCTION}

Imidazolium salts (IMSs) are best known for their applications in organic synthesis at room-temperature ionic liquids, or as precursors of stable carbenes, but they also show important biological properties such as antimicrobial activity. A large variety of these salts have been used as anti-inflammatory, antibacterial, antifungal and thromboxane synthetase enzyme inhibitor (Dominianni, Yen, 1989; Odžak, Skoc```bušcc', Maravic', 2013; Riduan, Zhang, 2013; Elshaarawy et al., 2014; Reinhardt et al., 2014).

Imidazole derived NHC precursors are known in the field of organometallic chemistry for more than five decades and the imidazole ring presents a structural fragment that plays an important role in many biological systems such as enzymes, metallo-proteins as well as in natural products and anticancer drugs (Jaouen, 2006). It also serves as a good ligand in various transition metal

\footnotetext{
*Correspondence: E. P. Çoban. Department of Biological Sciences. Faculty of Arts and Sciences. Adnan Menderes University, 09010 - Aydin, Turkey. E-mail: epoyrazoglu@adu.edu.tr
}

complexes (Navarro, Lippert, 2001).

Several sites around IMS are amenable to modification: (i) the nitrogen substituents (1 and 12) and (ii) the backbone carbon substituents ( 2 and $\mathbf{1 3}$ ). IMSs were prepared with different alkyl and aryl groups to establish the contributions of the type and size of the substituents to the activity. The introduction of sterically hindered groups to the nitrogen atoms that are the part of aromatic rings were believed to influence the activity.

One of the first instances of the use of IMSs as an antimicrobial agent was reported by Demberelnymba et al. (2004), in which a series of $N$-alkyl- $N$-methylimidazolium halides, and $N$-alkyl- $N$-hydroxyethylimidazolium chlorides were found to possess low MIC values against a range of microbes. They stated that the antibacterial and fungicidal activities were greatly affected by their chain length, the type of substituted functional groups, and their position in the imidazolium ring.

Based on these studies, we have discussed the synthesis and characterization of unsymmetrically substituted imidazolium salts and evaluated their antimicrobial properties. 


\section{MATERIAL AND METHODS}

\section{Material and measurements}

${ }^{1} \mathrm{H}$ - and ${ }^{13} \mathrm{C}$-NMR measurements were performed using a Varian Mercury 400 spectrometer operating at 400 and $100 \mathrm{MHz}$, respectively. NMR multiplicities are abbreviated as follows: s, singlet; d, doublet; t, triplet; m, multiplet signal. Coupling constants $J$ are given in $\mathrm{Hz}$. Melting points were measured in open capillary tubes with a Stuart-SMP30 melting point apparatus.

\section{Synthesis of 1-5}

A solution of $N$-(2,4,6-trimethylphenyl) imidazole $(2.0 \mathrm{mmol})$ (Zeng et al., 2010) in toluene $(10.0 \mathrm{~mL})$ was added slowly to 2,4,6-trimethylbenzyl bromide/2,4,5,6tetramethylbenzyl bromide/2,3,4,5,6-pentamethylbenzyl bromide (Van der Made, Van der Made, 1993) /1-bromoethanole/2-chloroethylamine hydrochloride $(2.0 \mathrm{mmol})$ at $110{ }^{\circ} \mathrm{C}$ for $18 \mathrm{~h}$. Diethylether $(15.0 \mathrm{~mL})$ was added to obtain a white crystalline solid which was filtered off. The solid was washed with $\mathrm{Et}_{2} \mathrm{O}(3 \times 15.0$ $\mathrm{mL}$ ), and dried under vacuum. The crude product was recrystallized from $\mathrm{CH}_{2} \mathrm{Cl}_{2} / \mathrm{Et}_{2} \mathrm{O}$ (Compound for 1-3 Günay, Çoğaşlığlu, Fırıncı (2015), compound 4,5 for Gençay (2013)).

Compound 1: N-(2,4,6-trimethylphenyl)-N'-(2,4,6trimethylbenzyl)imidazolium bromide

Yield: \% 80. m.p.: $273-275^{\circ} \mathrm{C} .{ }^{1} \mathrm{H}-\mathrm{NMR}(\boldsymbol{\delta}, 400$ $\left.\mathrm{MHz}, \mathrm{CDCl}_{3}\right): 1.96\left[\mathrm{~s}, 6 \mathrm{H}, \mathrm{C}_{6} \mathrm{H}_{2}\left(\mathrm{CH}_{3}\right)_{3}-\mathrm{O}-\mathrm{CH}_{3}\right] ; 2.03$ $\left[\mathrm{s}, 6 \mathrm{H}, \mathrm{C}_{6} \mathrm{H}_{2}\left(\mathrm{CH}_{3}\right)_{3}-\mathrm{o}-\mathrm{CH}_{3}\right] ; 2.25\left[\mathrm{~s}, 3 \mathrm{H}, \mathrm{C}_{6} \mathrm{H}_{2}\left(\mathrm{CH}_{3}\right)_{3}-\right.$ $\left.p-\mathrm{CH}_{3}\right] ; 2.29\left[\mathrm{~s}, 3 \mathrm{H}, \mathrm{C}_{6} \mathrm{H}_{2}\left(\mathrm{CH}_{3}\right)_{3}-p-\mathrm{CH}_{3}\right] ; 5.92[\mathrm{~s}, 2 \mathrm{H}$, $\left.\mathrm{NCH}_{2} \mathrm{C}_{6} \mathrm{H}_{2}\left(\mathrm{CH}_{3}\right)_{3}\right] ; 6.89[\mathrm{~s}, 1 \mathrm{H}, \mathrm{NCHCHN}] ; 6.94[\mathrm{~s}, 1 \mathrm{H}$, $\mathrm{NCHCHN}] ; 7.17\left[\mathrm{~d}, 2 \mathrm{H}, \mathrm{NCH}_{2} \mathrm{C}_{6} \mathrm{H}_{2}\left(\mathrm{CH}_{3}\right)_{3}\right] ; 7.21[\mathrm{~s}, 2 \mathrm{H}$, $\left.\mathrm{NC}_{6} \mathrm{H}_{2}\left(\mathrm{CH}_{3}\right)_{3}\right] ; 10.39$ [s, $\left.1 \mathrm{H}, \mathrm{NCHN}\right] .{ }^{13} \mathrm{C}-\mathrm{NMR}(\boldsymbol{\delta}, 100$ $\left.\mathrm{MHz}, \mathrm{CDCl}_{3}\right): 17.6\left[\mathrm{C}_{6} \mathrm{H}_{2}\left(\mathrm{CH}_{3}\right)_{3}\right] ; 19.9\left[\mathrm{C}_{6} \mathrm{H}_{2}\left(\mathrm{CH}_{3}\right)_{3}\right]$; $21.0\left[\mathrm{CH}_{2} \mathrm{C}_{6} \mathrm{H}_{2}\left(\mathrm{CH}_{3}\right)_{3}\right] ; 21.0\left[\mathrm{CH}_{2} \mathrm{C}_{6} \mathrm{H}_{2}\left(\mathrm{CH}_{3}\right)_{3}\right]$; $48.6\left[\mathrm{NCH}_{2} \mathrm{C}_{6} \mathrm{H}_{2}\left(\mathrm{CH}_{3}\right)_{3}\right] ; 121.7[\mathrm{NCHCHN}] ; 123.6$ [NCHCHN]; $125.7\left[\mathrm{C}_{6} \mathrm{H}_{2}\left(\mathrm{CH}_{3}\right)_{3}\right] ; 129.8\left[\mathrm{C}_{6} \mathrm{H}_{2}\left(\mathrm{CH}_{3}\right)_{3}\right]$; $129.9\left[\mathrm{C}_{6} \mathrm{H}_{2}\left(\mathrm{CH}_{3}\right)_{3}\right] ; 130.6\left[\mathrm{C}_{6} \mathrm{H}_{2}\left(\mathrm{CH}_{3}\right)_{3}\right] ; 134.1$ $\left[\mathrm{CH}_{2} \mathrm{C}_{6} \mathrm{H}_{2}\left(\mathrm{CH}_{3}\right)_{3}\right] ; 137.3\left[\mathrm{CH}_{2} \mathrm{C}_{6} \mathrm{H}_{2}\left(\mathrm{CH}_{3}\right)_{3}\right] ; 138.1$ $\left[\mathrm{CH}_{2} \mathrm{C}_{6} \mathrm{H}_{2}\left(\mathrm{CH}_{3}\right)_{3}\right] ; 139.9\left[\mathrm{CH}_{2} \mathrm{C}_{6} \mathrm{H}_{2}\left(\mathrm{CH}_{3}\right)_{3}\right] ; 141.2$ [NCHN].

Compound 2: N-(2,4,6-trimethylphenyl)-N'-(2,3,5,6tetramethylbenzyl)imidazolium bromide

Yield: \% 80. m.p.: $280-283{ }^{\circ} \mathrm{C} .{ }^{1} \mathrm{H}-\mathrm{NMR}(\boldsymbol{\delta}, 400$ $\left.\mathrm{MHz}, \mathrm{CDCl}_{3}\right): 2.01\left[\mathrm{~s}, 6 \mathrm{H}, \mathrm{C}_{6} \mathrm{H}_{2}\left(\mathrm{CH}_{3}\right)_{3}-\mathrm{o}-\mathrm{CH}_{3}\right] ; 2.18$ $\left[\mathrm{s}, 6 \mathrm{H}, \mathrm{C}_{6} \mathrm{H}\left(\mathrm{CH}_{3}\right)_{4}-\mathrm{o}-\mathrm{CH}_{3}\right] ; 2.23\left[\mathrm{~s}, 6 \mathrm{H}, \mathrm{C}_{6} \mathrm{H}\left(\mathrm{CH}_{3}\right)_{4}-\right.$
$\left.m-\mathrm{CH}_{3}\right] ; 2.26\left[\mathrm{~s}, 6 \mathrm{H}, \mathrm{C}_{6} \mathrm{H}_{2}\left(\mathrm{CH}_{3}\right)_{3}-p-\mathrm{CH}_{3}\right] ; 5.95[\mathrm{~s}, 2 \mathrm{H}$, $\left.\mathrm{NCH}_{2} \mathrm{C}_{6} \mathrm{H}\left(\mathrm{CH}_{3}\right)_{4}\right] ; 6.91[\mathrm{t}, 1 \mathrm{H}, \mathrm{NCHCHN}] ; 6.99[\mathrm{t}, 1 \mathrm{H}$, $\mathrm{NCHCHN}] ; 7.15\left[\mathrm{~s}, 2 \mathrm{H}, \mathrm{NC}_{6} \mathrm{H}_{2}\left(\mathrm{CH}_{3}\right)_{3}\right] ; 7.27[\mathrm{~s}, 1 \mathrm{H}$, $\left.\mathrm{C}_{6} H\left(\mathrm{CH}_{3}\right)_{4}\right] ; 10.29[\mathrm{~s}, 1 \mathrm{H}, \mathrm{NCHN}] \cdot{ }^{13} \mathrm{C}-\mathrm{NMR}(\boldsymbol{\delta}, 100$ $\left.\mathrm{MHz}, \mathrm{CDCl}_{3}\right): 15.8\left[\mathrm{C}_{6} \mathrm{H}_{2}\left(\mathrm{CH}_{3}\right)_{3}\right] ; 17.6\left[\mathrm{C}_{6} \mathrm{H}_{2}\left(\mathrm{CH}_{3}\right)_{3}\right] ; 20.4$ $\left[\mathrm{C}_{6} \mathrm{H}\left(\mathrm{CH}_{3}\right)_{4}\right] ; 21.0\left[\mathrm{C}_{6} \mathrm{H}\left(\mathrm{CH}_{3}\right)_{4}\right] ; 49.1\left[\mathrm{NCH}_{2} \mathrm{C}_{6}\left(\mathrm{CH}_{3}\right)_{5}\right]$; $121.8[\mathrm{NCHCHN}] ; 123.7[\mathrm{NCHCHN}] ; 128.4\left[\mathrm{C}_{6} \mathrm{H}\left(\mathrm{CH}_{3}\right)_{4}\right]$; $129.8\left[\mathrm{C}_{6} \mathrm{H}\left(\mathrm{CH}_{3}\right)_{4}\right] ; 130.6\left[\mathrm{C}_{6} \mathrm{H}\left(\mathrm{CH}_{3}\right)_{4}\right] ; 133.4$ $\left[\mathrm{C}_{6} \mathrm{H}\left(\mathrm{CH}_{3}\right)_{4}\right] ; 134.0\left[\mathrm{C}_{6} \mathrm{H}_{2}\left(\mathrm{CH}_{3}\right)_{3}\right] ; 134.1\left[\mathrm{C}_{6} \mathrm{H}_{2}\left(\mathrm{CH}_{3}\right)_{3}\right]$; $134.9\left[\mathrm{C}_{6} \mathrm{H}_{2}\left(\mathrm{CH}_{3}\right)_{3}\right] ; 137.2\left[\mathrm{C}_{6} \mathrm{H}_{2}\left(\mathrm{CH}_{3}\right)_{3}\right] ; 141.2[\mathrm{NCHN}]$.

Compound 3: N-(2,4,6-trimethylphenyl)-N'-(2,3,4,5,6pentamethylbenzyl)imidazolium bromide

Yield: \% 85. m.p.: $290-293{ }^{\circ} \mathrm{C} .{ }^{1} \mathrm{H}-\mathrm{NMR}(\boldsymbol{\delta}, 400$ $\left.\mathrm{MHz}, \mathrm{CDCl}_{3}\right): 2.07\left[\mathrm{~s}, 6 \mathrm{H}, \mathrm{C}_{6} \mathrm{H}_{2}\left(\mathrm{CH}_{3}\right)_{3}-\mathrm{o}-\mathrm{CH}_{3}\right] ; 2.23[\mathrm{~s}, 6 \mathrm{H}$, $\left.\mathrm{C}_{6}\left(\mathrm{CH}_{3}\right)_{5}-\mathrm{o}-\mathrm{CH}_{3}\right] ; 2.26\left[\mathrm{~s}, 3 \mathrm{H}, \mathrm{C}_{6} \mathrm{H}_{2}\left(\mathrm{CH}_{3}\right)_{3}-p-\mathrm{CH}_{3}\right] ; 2.28[\mathrm{~s}$, $\left.6 \mathrm{H}, \mathrm{C}_{6}\left(\mathrm{CH}_{3}\right)_{5}-m-\mathrm{CH}_{3}\right] ; 2.32\left[\mathrm{~s}, 3 \mathrm{H}, \mathrm{C}_{6}\left(\mathrm{CH}_{3}\right)_{5}-p-\mathrm{CH}_{3}\right] ; 6.01$ $\left[\mathrm{s}, 2 \mathrm{H}, \mathrm{NCH}_{2} \mathrm{C}_{6}\left(\mathrm{CH}_{3}\right)_{5}\right] ; 6.98[\mathrm{~s}, 1 \mathrm{H}, \mathrm{NCHCHN}] ; 7.26[\mathrm{~s}$, $1 \mathrm{H}, \mathrm{NCHCHN}] ; 10.32[\mathrm{~s}, 1 \mathrm{H}, \mathrm{NCHN}] .{ }^{13} \mathrm{C}-\mathrm{NMR}(\boldsymbol{\delta}, 100$ $\left.\mathrm{MHz}, \mathrm{CDCl}_{3}\right)$ : $16.7\left[\mathrm{C}_{6} \mathrm{H}_{2}\left(\mathrm{CH}_{3}\right)_{3}-\mathrm{O}-\mathrm{CH}_{3}\right] ; 16.9\left[\mathrm{C}_{6}\left(\mathrm{CH}_{3}\right)_{5}-\right.$ $\left.o-\mathrm{CH}_{3}\right] ; 17.2\left[\mathrm{C}_{6}\left(\mathrm{CH}_{3}\right)_{5}-m-\mathrm{CH}_{3}\right] ; 17.6\left[\mathrm{C}_{6} \mathrm{H}_{2}\left(\mathrm{CH}_{3}\right)_{3}-p-\right.$ $\left.\mathrm{CH}_{3}\right] ; 21.0\left[\mathrm{C}_{6}\left(\mathrm{CH}_{3}\right)_{5}-p-\mathrm{CH}_{3}\right] ; 49.8\left[\mathrm{NCH}_{2} \mathrm{C}_{6}\left(\mathrm{CH}_{3}\right)_{5}\right] ; 121.9$ $[\mathrm{NCHCHN}] ; 123.4[\mathrm{NCHCHN}] ; 125.7\left[\mathrm{C}_{6}\left(\mathrm{CH}_{3}\right)_{5}\right] ; 129.8$ $\left[C_{6}\left(\mathrm{CH}_{3}\right)_{5}\right] ; 130.6\left[\mathrm{C}_{6}\left(\mathrm{CH}_{3}\right)_{5}\right] ; 133.5\left[\mathrm{C}_{6}\left(\mathrm{CH}_{3}\right)_{5}\right] ; 133.7$ $\left[C_{6} \mathrm{H}_{2}\left(\mathrm{CH}_{3}\right)_{3}\right] ; 134.1\left[\mathrm{C}_{6} \mathrm{H}_{2}\left(\mathrm{CH}_{3}\right)_{3}\right] ; 137.1\left[\mathrm{C}_{6} \mathrm{H}_{2}\left(\mathrm{CH}_{3}\right)_{3}\right]$; $137.2\left[\mathrm{C}_{6} \mathrm{H}_{2}\left(\mathrm{CH}_{3}\right)_{3}\right] ; 141.2[\mathrm{NCHN}]$.

Compound 4: N-(2,4,6-trimethylphenyl)-N'-

(hydroxyethyl)imidazolium bromide

Yield: $85 \%$. m.p.: $163-165{ }^{\circ} \mathrm{C} .{ }^{1} \mathrm{H}-\mathrm{NMR}(\boldsymbol{\delta}, 400$ $\mathrm{MHz}, \mathrm{DMSO}): 2.01\left[\mathrm{~s}, 6 \mathrm{H}, \mathrm{C}_{6} \mathrm{H}_{2}\left(\mathrm{CH}_{3}\right)_{3}-\mathrm{o}-\mathrm{CH}_{3}\right] ; 2.31$ $\left[\mathrm{s}, 3 \mathrm{H}, \mathrm{C}_{6} \mathrm{H}_{2}\left(\mathrm{CH}_{3}\right)_{3}-p-\mathrm{CH}_{3}\right] ; 3.81[\mathrm{t}, J=5.0 \mathrm{~Hz}, 2 \mathrm{H}$, $\left.\mathrm{NCH}_{2} \mathrm{CH}_{2} \mathrm{OH}\right] ; 4.36\left[\mathrm{t}, J=5.0 \mathrm{~Hz}, 2 \mathrm{H}, \mathrm{NCH}_{2} \mathrm{CH}_{2} \mathrm{OH}\right] ; 7.12$ [s, $\left.2 \mathrm{H}, \mathrm{C}_{6} \mathrm{H}_{2}\left(\mathrm{CH}_{3}\right)_{3}\right] ; 7.91[\mathrm{~s}, 1 \mathrm{H}, \mathrm{NCHCHN}] ; 8.08[\mathrm{~s}, 1 \mathrm{H}$, $\mathrm{NCHCHN}] ; 9.47[\mathrm{~s}, 1 \mathrm{H}, \mathrm{NCHN}] .{ }^{13} \mathrm{C}-\mathrm{NMR}(\boldsymbol{\delta}, 100 \mathrm{MHz}$, DMSO): $17.6\left[\mathrm{C}_{6} \mathrm{H}_{2}\left(\mathrm{CH}_{3}\right)_{3}-o-\mathrm{CH}_{3}\right] ; 21.2\left[\mathrm{C}_{6} \mathrm{H}_{2}\left(\mathrm{CH}_{3}\right)_{3}-p-\right.$ $\left.\mathrm{CH}_{3}\right] ; 52.6\left[\mathrm{NCH}_{2} \mathrm{CH}_{2} \mathrm{OH}\right] ; 59.7\left[\mathrm{NCH}_{2} \mathrm{CH}_{2} \mathrm{OH}\right] ; 124.1$ [NCHCHN]; 124.4 [NCHCHN]; $129.9\left[\mathrm{C}_{6} \mathrm{H}_{2}\left(\mathrm{CH}_{3}\right)_{3}\right]$; $131.9\left[\mathrm{C}_{6} \mathrm{H}_{2}\left(\mathrm{CH}_{3}\right)_{3}\right] ; 135.0\left[\mathrm{C}_{6} \mathrm{H}_{2}\left(\mathrm{CH}_{3}\right)_{3}\right] ; 138.4$ $\left[\mathrm{C}_{6} \mathrm{H}_{2}\left(\mathrm{CH}_{3}\right)_{3}\right] ; 140.9$ [NCHN].

Compound 5: N-(2,4,6-trimethylphenyl)-N'-

(ethylamine)imidazolium chloride hydrochloride

Yield: 80\%. m.p.: 203-205 ${ }^{\circ} \mathrm{C} .{ }^{1} \mathrm{H}-\mathrm{NMR}(\boldsymbol{\delta}$, $400 \mathrm{MHz}, \mathrm{DMSO}): 2.06$ [s, $6 \mathrm{H}, \mathrm{C}_{6} \mathrm{H}_{2}\left(\mathrm{CH}_{3}\right)_{3}-0-\mathrm{CH}_{3}$ ]; $2.29\left[\mathrm{~s}, 3 \mathrm{H}, \mathrm{C}_{6} \mathrm{H}_{2}\left(\mathrm{CH}_{3}\right)_{3}-p-\mathrm{CH}_{3}\right] ; 3.86[\mathrm{t}, J=5.85 \mathrm{~Hz}$, $\left.2 \mathrm{H}, \mathrm{NCH}_{2} \mathrm{CH}_{2} \mathrm{NH}_{2} . \mathrm{HCl}\right] ; 4.68[\mathrm{t}, J=5.85 \mathrm{~Hz}, 2 \mathrm{H}$, $\left.\mathrm{NCH}_{2} \mathrm{CH}_{2} \mathrm{NH}_{2} . \mathrm{HCl}\right] ; 7.09\left[\mathrm{~s}, 2 \mathrm{H}, \mathrm{C}_{6} \mathrm{H}_{2}\left(\mathrm{CH}_{3}\right)_{3}\right] ; 7.93[\mathrm{~s}$, $1 \mathrm{H}, \mathrm{NCHCHN}] ; 8.24$ [s, $1 \mathrm{H}, \mathrm{NCHCHN}] ; 8.55[\mathrm{br}, 1 \mathrm{H}$, $\left.\mathrm{NH}_{2} . \mathrm{HCl}\right] ; 9.68$ [s, $\left.1 \mathrm{H}, \mathrm{NCHN}\right] .{ }^{13} \mathrm{C}-\mathrm{NMR}(\boldsymbol{\delta}, 100 \mathrm{MHz}$, 
DMSO): $17.8\left[\mathrm{C}_{6} \mathrm{H}_{2}\left(\mathrm{CH}_{3}\right)_{3}-\mathrm{o}-\mathrm{CH}_{3}\right] ; 21.0\left[\mathrm{C}_{6} \mathrm{H}_{2}\left(\mathrm{CH}_{3}\right)_{3}-\mathrm{p}-\right.$ $\left.\mathrm{CH}_{3}\right] ; 38.1\left[\mathrm{NCH}_{2} \mathrm{CH}_{2} \mathrm{NH}_{2} \cdot \mathrm{HCl}\right] ; 47.3\left[\mathrm{NCH}_{2} \mathrm{CH}_{2} \mathrm{NH}_{2}\right.$. $\mathrm{HCl}] ; 123.8$ [NCHCHN]; $124.3[\mathrm{NCHCHN}] ; 129.7$ $\left[\mathrm{C}_{6} \mathrm{H}_{2}\left(\mathrm{CH}_{3}\right)_{3}\right] ; 131.4\left[\mathrm{C}_{6} \mathrm{H}_{2}\left(\mathrm{CH}_{3}\right)_{3}\right] ; 134.8\left[\mathrm{C}_{6} \mathrm{H}_{2}\left(\mathrm{CH}_{3}\right)_{3}\right]$; $138.7\left[\mathrm{C}_{6} \mathrm{H}_{2}\left(\mathrm{CH}_{3}\right)_{3}\right] ; 140.6[\mathrm{NCHN}]$.

\section{Synthesis of 6}

1-Ferrocenylethanol $(1.0 \mathrm{mmol})$ and $N-(2,4,6-$ trimethyphenyl)imidazole $(1.1 \mathrm{mmol})$ were dissolved in acetic acid $(3.0 \mathrm{~mL})$ and stirred at $60^{\circ} \mathrm{C}$ for $7 \mathrm{~h}$. After removing most of acetic acid, a solution of $\mathrm{LiCl}(4.0$ $\mathrm{mmol})$ in EtOH (20.0 mL) was added, and stirred for $8 \mathrm{~h}$ at room temperature. After removing the volatiles, filtered through Celite, the crude was purified from $\mathrm{CH}_{2} \mathrm{Cl}_{2} / \mathrm{Et}_{2} \mathrm{O}$ (Yenisar1, 2014; Seo et al., 2003).

Compound 6: N-(ferrocenylethyl)-N'-(2,4,6trimethylphenyl)imidazolium chloride

Yield: $62 \%$. ${ }^{1} \mathrm{H}-\mathrm{NMR}(\boldsymbol{\delta}, 400 \mathrm{MHz}, \mathrm{DMSO}): 1.97$ $\left[\mathrm{s}, 9 \mathrm{H}, \mathrm{C}_{6} \mathrm{H}_{2}\left(\mathrm{CH}_{3}\right)_{3}-o, p-\left(\mathrm{CH}_{3}\right)\right] ; 2.30\left[\mathrm{~s}, 3 \mathrm{H}, \mathrm{FcCHCH}_{3}\right]$; $4.23[\mathrm{~s}, 5 \mathrm{H}, \mathrm{Fc}-H] ; 4.39$ [s, $2 \mathrm{H}, \mathrm{Fc}-H] ; 4.44$ [s, 2H, Fc$H]$; 5.68-5.82 [m, $\left.1 \mathrm{H}, \mathrm{FcCHCH}_{3}\right] ; 7.11[\mathrm{~d}, J=6.7 \mathrm{~Hz}$, $\left.2 \mathrm{H}, \mathrm{C}_{6} \mathrm{H}_{2}\left(\mathrm{CH}_{3}\right)_{3}\right] ; 7.92[\mathrm{~s}, 1 \mathrm{H}, \mathrm{NCHCHN}] ; 8.18[\mathrm{~s}, 1 \mathrm{H}$, $\mathrm{NCHC} H \mathrm{~N}] ; 9.87[\mathrm{~s}, 1 \mathrm{H}, \mathrm{NCHN}] .{ }^{13} \mathrm{C}-\mathrm{NMR}(\delta, 100 \mathrm{MHz}$, DMSO): $16.8\left[\mathrm{C}_{6} \mathrm{H}_{2}\left(\mathrm{CH}_{3}\right)_{3}-O-\left(\mathrm{CH}_{3}\right)\right] ; 16.9\left[\mathrm{C}_{6} \mathrm{H}_{2}\left(\mathrm{CH}_{3}\right)_{3}-O-\right.$ $\left.\left(\mathrm{CH}_{3}\right)\right] ; 20.2\left[\mathrm{C}_{6} \mathrm{H}_{2}\left(\mathrm{CH}_{3}\right)_{3}-p-\left(\mathrm{CH}_{3}\right)\right] ; 21.1\left[\mathrm{FcCHCH}_{3}\right] ; 55.8$ $\left[\mathrm{FcCHCH}_{3}\right] ; 65.9[\mathrm{Fc}-\mathrm{C}] ; 67.3[\mathrm{Fc}-\mathrm{C}] ; 68.1[\mathrm{Fc}-\mathrm{C}] ; 68.6$ $[\mathrm{Fc}-\mathrm{C}] ; 68.8[\mathrm{Fc}-\mathrm{C}] ; 78.8[\mathrm{Fc}-\mathrm{C}] ; 79.1[\mathrm{Fc}-\mathrm{C}] ; 79.4[\mathrm{Fc}-C]$; $87.3[\mathrm{Fc}-\mathrm{C}] ; 121.4[\mathrm{NCHCHN}] ; 123.9[\mathrm{NCHCHN}] ; 128.9$ $\left[\mathrm{C}_{6} \mathrm{H}_{2}\left(\mathrm{CH}_{3}\right)_{3}\right] ; 131.1\left[\mathrm{C}_{6} \mathrm{H}_{2}\left(\mathrm{CH}_{3}\right)_{3}\right] ; 134.0\left[\mathrm{C}_{6} \mathrm{H}_{2}\left(\mathrm{CH}_{3}\right)_{3}\right]$; $136.3\left[\mathrm{C}_{6} \mathrm{H}_{2}\left(\mathrm{CH}_{3}\right)_{3}\right] ; 140.0$ [NCHN].

\section{Synthesis of 7-9}

These compounds were synthesized according to the method in the literature (Günay et al., 2009).

\section{Compound 7: N-(methyl)-N'-(2,3,5,6-}

tetramethylbenzyl)imidazolium bromide

Yield: $83 \%$, m.p.: $123-125^{\circ} \mathrm{C} .{ }^{1} \mathrm{H}-\mathrm{NMR}(\delta, 400$ $\left.\mathrm{MHz}, \mathrm{CDCl}_{3}\right): 2.16\left[\mathrm{~s}, 6 \mathrm{H}, \mathrm{C}_{6} \mathrm{H}\left(\mathrm{CH}_{3}\right)_{4}-\mathrm{o}-\mathrm{CH}_{3}\right] ; 2.21[\mathrm{~s}$, $\left.6 \mathrm{H}, \mathrm{C}_{6} \mathrm{H}\left(\mathrm{CH}_{3}\right)_{4}-m-\mathrm{CH}_{3}\right] ; 4.09\left[\mathrm{~s}, 3 \mathrm{H}, \mathrm{NCH}_{3}\right] ; 5.59[\mathrm{~s}, 2 \mathrm{H}$, $\left.\mathrm{NCH}_{2} \mathrm{C}_{6} \mathrm{H}\left(\mathrm{CH}_{3}\right)_{4}\right] ; 6.90$ [d, $\left.1 \mathrm{H}, J=1.6 \mathrm{~Hz}, \mathrm{NCHCHN}\right]$; $7.01\left[\mathrm{~s}, 1 \mathrm{H}, \mathrm{C}_{6} H\left(\mathrm{CH}_{3}\right)_{4}\right] ; 7.51[\mathrm{~d}, 1 \mathrm{H}, J=1.6 \mathrm{~Hz}$, $\mathrm{NCHC} H \mathrm{~N}] ; 10.02[\mathrm{~s}, 1 \mathrm{H}, \mathrm{NC} H \mathrm{~N}] .{ }^{13} \mathrm{C}-\mathrm{NMR}(\delta, 100$ $\left.\mathrm{MHz}, \mathrm{CDCl}_{3}\right): 16.1\left[\mathrm{C}_{6} \mathrm{H}\left(\mathrm{CH}_{3}\right)_{4}-\mathrm{o}-\mathrm{CH}_{3}\right] ; 20.6\left[\mathrm{C}_{6} \mathrm{H}\left(\mathrm{CH}_{3}\right)_{4}\right.$ $\left.m-\mathrm{CH}_{3}\right] ; 37.3\left[\mathrm{NCH}_{3}\right] ; 48.8\left[\mathrm{NCH}_{2} \mathrm{C}_{6} \mathrm{H}\left(\mathrm{CH}_{3}\right)_{4}\right] ; 121.1$ [NCHCHN]; $123.8[\mathrm{NCHCHN}] ; 128.1\left[\mathrm{C}_{6} \mathrm{H}\left(\mathrm{CH}_{3}\right)_{4}\right] ; 133.8$ $\left[\mathrm{C}_{6} \mathrm{H}\left(\mathrm{CH}_{3}\right)_{4}\right] ; 134.3\left[\mathrm{C}_{6} \mathrm{H}\left(\mathrm{CH}_{3}\right)_{4}\right] ; 135.2\left[\mathrm{C}_{6} \mathrm{H}\left(\mathrm{CH}_{3}\right)_{4}\right]$; $137.2[\mathrm{NCHN}]$.
Compound 8: N-(methyl)-N'-(2,3,4,5,6-

pentamethylbenzyl)imidazolium bromide

Yield: 94\%, m.p.: $192-194{ }^{\circ} \mathrm{C} .{ }^{1} \mathrm{H}-\mathrm{NMR}(\delta, 400$ $\left.\mathrm{MHz}, \mathrm{CDCl}_{3}\right): 2.17\left[\mathrm{~s}, 6 \mathrm{H}, \mathrm{C}_{6}\left(\mathrm{CH}_{3}\right)_{5}-\mathrm{o}-\mathrm{CH}_{3}\right] ; 2.18[\mathrm{~s}, 6 \mathrm{H}$, $\left.\mathrm{C}_{6}\left(\mathrm{CH}_{3}\right)_{5}-m-\mathrm{CH}_{3}\right] ; 2.21\left[\mathrm{~s}, 3 \mathrm{H}, \mathrm{C}_{6}\left(\mathrm{CH}_{3}\right)_{5}-p-\mathrm{CH}_{3}\right] ; 4.08$ $\left[\mathrm{s}, 3 \mathrm{H}, \mathrm{NCH}_{3}\right] ; 5.57\left[\mathrm{~s}, 2 \mathrm{H}, \mathrm{NCH}_{2} \mathrm{C}_{6}\left(\mathrm{CH}_{3}\right)_{5}\right] ; 6.91[\mathrm{~d}$, $\left.1 \mathrm{H}, J=1.6 \mathrm{~Hz}, \mathrm{NCHCHNCH}_{3}\right] ; 7.54[\mathrm{~d}, 1 \mathrm{H}, J=1.6 \mathrm{~Hz}$, $\left.\mathrm{NCHCHNCH}_{3}\right] ; 9.94[\mathrm{~s}, 1 \mathrm{H}, \mathrm{NCHN}] \cdot{ }^{13} \mathrm{C}-\mathrm{NMR}(\delta, 100$ $\left.\mathrm{MHz}, \mathrm{CDCl}_{3}\right): 17.0\left[\mathrm{C}_{6}\left(\mathrm{CH}_{3}\right)_{5}-\mathrm{o}-\mathrm{CH}_{3}\right] ; 17.1\left[\mathrm{C}_{6}\left(\mathrm{CH}_{3}\right)_{5}-\right.$ $\left.m-\mathrm{CH}_{3}\right] ; 17.4\left[\mathrm{C}_{6}\left(\mathrm{CH}_{3}\right)_{5}-p-\mathrm{CH}_{3}\right] ; 37.2\left[\mathrm{NCH}_{3}\right] ; 49.3$ $\left[\mathrm{NCH}_{2} \mathrm{C}_{6}\left(\mathrm{CH}_{3}\right)_{5}\right] ; 121.1[\mathrm{NCHCHN}] ; 123.9$ [NCHCHN]; $125.4\left[\mathrm{C}_{6}\left(\mathrm{CH}_{3}\right)_{5}\right] ; 133.8\left[\mathrm{C}_{6}\left(\mathrm{CH}_{3}\right)_{5}\right] ; 133.9\left[\mathrm{C}_{6}\left(\mathrm{CH}_{3}\right)_{5}\right]$; $136.9\left[\mathrm{C}_{6}\left(\mathrm{CH}_{3}\right)_{5}\right] ; 137.5[\mathrm{NCHN}]$.

\section{Compound 9: N-(methyl)-N'-(2-methoxyethyl)} imidazolium chloride

Yield: $72 \%$ (air sensitive). ${ }^{1} \mathrm{H}-\mathrm{NMR}(\delta, 400$ $\mathrm{MHz}, \mathrm{CDCl}_{3}$ ): $3.30\left[\mathrm{~s}, 3 \mathrm{H}, \mathrm{NCH}_{3}\right] ; 3.70-3.72[\mathrm{~m}, 2 \mathrm{H}$, $\left.\mathrm{NCH}_{2} \mathrm{CH}_{2} \mathrm{OCH}_{3}\right] ; 4.05\left[\mathrm{~s}, 3 \mathrm{H}, \mathrm{NCH}_{2} \mathrm{CH}_{2} \mathrm{OCH}_{3}\right] ; 4.52-4.54$ $\left[\mathrm{m}, 2 \mathrm{H}, \mathrm{NCH}_{2} \mathrm{CH}_{2} \mathrm{OCH}_{3}\right]$; 7.57-7.59 [m, 2H, $\left.\mathrm{NCHCHN}\right]$; 10.37 [s, 1H, NCHN].

\section{Synthesis of 10-12}

These compounds were synthesized according to the literature method (Compounds for 10, 11 Günay et al. (2009), compound for 12 Günay, Çoğaşlığlu (2016)).

\section{Compound 10: N-(butyl)-N'-(2,4,6-trimethylbenzyl) imidazolium bromide}

Yield: $84 \%$. m.p.: $100{ }^{\circ} \mathrm{C} .{ }^{1} \mathrm{H}-\mathrm{NMR}(\delta, 400 \mathrm{MHz}$, $\mathrm{CDCl}_{3}$ ): 0.83 [t, 3H, $J=7.2 \mathrm{~Hz}, \mathrm{CH}_{3} \mathrm{CH}_{2} \mathrm{CH}_{2} \mathrm{CH}_{2} \mathrm{~N}$; $1.26\left[\mathrm{~m}, 2 \mathrm{H}, \mathrm{CH}_{3} \mathrm{CH}_{2} \mathrm{CH}_{2} \mathrm{CH}_{2} \mathrm{~N}\right] ; 1.81[\mathrm{~m}, 2 \mathrm{H}$, $\left.\mathrm{CH}_{3} \mathrm{CH}_{2} \mathrm{CH}_{2} \mathrm{CH}_{2} \mathrm{~N}\right] ; 2.16$ [s, $\left.9 \mathrm{H}, \mathrm{C}_{6} \mathrm{H}_{2}\left(\mathrm{CH}_{3}\right)_{3}-o, p-\mathrm{CH}_{3}\right]$; $4.27\left[\mathrm{t}, 2 \mathrm{H}, J=7.2 \mathrm{~Hz}, \mathrm{CH}_{3} \mathrm{CH}_{2} \mathrm{CH}_{2} \mathrm{CH}_{2} \mathrm{~N}\right] ; 5.49$ [s, $\left.2 \mathrm{H}, \mathrm{NCH}_{2} \mathrm{C}_{6} \mathrm{H}_{2}\left(\mathrm{CH}_{3}\right)_{3}\right] ; 6.80\left[\mathrm{~s}, 2 \mathrm{H}, \mathrm{C}_{6} \mathrm{H}_{2}\left(\mathrm{CH}_{3}\right)_{3}\right] ; 6.80$ $[\mathrm{s}, 2 \mathrm{H}, \mathrm{NCHCHN}] ; 7.60[\mathrm{~s}, 2 \mathrm{H}, \mathrm{NCHCHN}] ; 10.26$ $[\mathrm{s}, 1 \mathrm{H}, \mathrm{NCHN}] \cdot{ }^{13} \mathrm{C}-\mathrm{NMR}\left(\delta, 100 \mathrm{MHz}, \mathrm{CDCl}_{3}\right)$ : $13.4\left[\mathrm{CH}_{3} \mathrm{CH}_{2} \mathrm{CH}_{2} \mathrm{CH}_{2} \mathrm{~N}\right] ; 19.4\left[\mathrm{CH}_{3} \mathrm{CH}_{2} \mathrm{CH}_{2} \mathrm{CH}_{2} \mathrm{~N}\right]$; $19.8\left[\mathrm{C}_{6} \mathrm{H}_{2}\left(\mathrm{CH}_{3}\right)_{3}-o-\mathrm{CH}_{3}\right] ; 21.0\left[\mathrm{C}_{6} \mathrm{H}_{2}\left(\mathrm{CH}_{3}\right)_{3}-p-\mathrm{CH}_{3}\right]$; $32.1\left[\mathrm{CH}_{3} \mathrm{CH}_{2} \mathrm{CH}_{2} \mathrm{CH}_{2} \mathrm{~N}\right] ; 47.8\left[\mathrm{CH}_{3} \mathrm{CH}_{2} \mathrm{CH}_{2} \mathrm{CH}_{2} \mathrm{~N}\right]$; $50.0\left[\mathrm{NCH}_{2} \mathrm{C}_{6} \mathrm{H}_{2}\left(\mathrm{CH}_{3}\right)_{3}\right] ; 120.6[\mathrm{NCHCHN}]$; $122.3[\mathrm{NCHCHN}] ; 125.3\left[\mathrm{C}_{6} \mathrm{H}_{2}\left(\mathrm{CH}_{3}\right)_{3}\right] ; 130.0$ $\left[\mathrm{C}_{6} \mathrm{H}_{2}\left(\mathrm{CH}_{3}\right)_{3}\right] ; 136.7\left[\mathrm{C}_{6} \mathrm{H}_{2}\left(\mathrm{CH}_{3}\right)_{3}\right] ; 138.0\left[\mathrm{C}_{6} \mathrm{H}_{2}\left(\mathrm{CH}_{3}\right)_{3}\right]$; 139.9 [NCHN].

\section{Compound 11: N-(butyl)-N'-(2,3,5,6-}

tetramethylbenzyl)imidazolium bromide

Yield: $81 \%$. m.p.: $110{ }^{\circ} \mathrm{C} .{ }^{1} \mathrm{H}-\mathrm{NMR}(\delta, 400 \mathrm{MHz}$, $\left.\mathrm{CDCl}_{3}\right): 0.85\left[\mathrm{t}, 3 \mathrm{H}, J=7.4 \mathrm{~Hz}, \mathrm{CH}_{3} \mathrm{CH}_{2} \mathrm{CH}_{2} \mathrm{CH}_{2} \mathrm{~N}\right]$; $1.30\left[\mathrm{~m}, 2 \mathrm{H}, \mathrm{CH}_{3} \mathrm{CH}_{2} \mathrm{CH}_{2} \mathrm{CH}_{2} \mathrm{~N}\right] ; 1.84[\mathrm{~m}, 2 \mathrm{H}$, 
$\left.\mathrm{CH}_{3} \mathrm{CH}_{2} \mathrm{CH}_{2} \mathrm{CH}_{2} \mathrm{~N}\right] ; 2.09$ [s, 6H, $\mathrm{C}_{6} \mathrm{H}\left(\mathrm{CH}_{3}\right)_{4}-\mathrm{o}-\mathrm{CH}_{3}$; $2.14\left[\mathrm{~s}, 6 \mathrm{H}, \mathrm{C}_{6} \mathrm{H}\left(\mathrm{CH}_{3}\right)_{4}-m-\mathrm{CH}_{3}\right] ; 4.29[\mathrm{t}, 2 \mathrm{H}, J=7.4$ $\mathrm{Hz}, \mathrm{CH}_{3} \mathrm{CH}_{2} \mathrm{CH}_{2} \mathrm{CH}_{2} \mathrm{~N}$ ]; 5.57 [s, $2 \mathrm{H}, \mathrm{NCH}_{2} \mathrm{C}_{6} \mathrm{H}\left(\mathrm{CH}_{3}\right)_{4}$ ]; $6.81[\mathrm{~s}, 1 \mathrm{H}, \mathrm{NCHCHN}] ; 6.95\left[\mathrm{~s}, 1 \mathrm{H}, \mathrm{C}_{6} \mathrm{H}_{\left.\left(\mathrm{CH}_{3}\right)_{4}\right] ; 7.59}\right.$ $[\mathrm{s}, 1 \mathrm{H}, \mathrm{NCHCHN}] ; 10.27[\mathrm{~s}, 1 \mathrm{H}, \mathrm{NCHN}] .{ }^{13} \mathrm{C}-\mathrm{NMR}$ $\left(\delta, 100 \mathrm{MHz}, \mathrm{CDCl}_{3}\right): 13.4\left[\mathrm{CH}_{3} \mathrm{CH}_{2} \mathrm{CH}_{2} \mathrm{CH}_{2} \mathrm{~N}\right] ; 15.8$ $\left[\mathrm{CH}_{3} \mathrm{CH}_{2} \mathrm{CH}_{2} \mathrm{CH}_{2} \mathrm{~N}\right] ; 19.4\left[\mathrm{C}_{6} \mathrm{H}\left(\mathrm{CH}_{3}\right)_{4}-\mathrm{o}-\mathrm{CH}_{3}\right] ; 20.4$ $\left[\mathrm{C}_{6} \mathrm{H}\left(\mathrm{CH}_{3}\right)_{4}-p-\mathrm{CH}_{3}\right] ; 32.1\left[\mathrm{CH}_{3} \mathrm{CH}_{2} \mathrm{CH}_{2} \mathrm{CH}_{2} \mathrm{~N}\right] ; 48.5$ $\left[\mathrm{CH}_{3} \mathrm{CH}_{2} \mathrm{CH}_{2} \mathrm{CH}_{2} \mathrm{~N}\right] ; 50.0\left[\mathrm{NCH}_{2} \mathrm{C}_{6} \mathrm{H}\left(\mathrm{CH}_{3}\right)_{4}\right] ; 120.8$ $[\mathrm{NCHCHN}] ; 122.4[\mathrm{NCHCHN}] ; 128.0\left[\mathrm{C}_{6} \mathrm{H}\left(\mathrm{CH}_{3}\right)_{4}\right]$; $129.7\left[C_{6} \mathrm{H}\left(\mathrm{CH}_{3}\right)_{4}\right] ; 133.4\left[C_{6} \mathrm{H}\left(\mathrm{CH}_{3}\right)_{4}\right] ; 134.0$ $\left[\mathrm{C}_{6} \mathrm{H}\left(\mathrm{CH}_{3}\right)_{4}\right] ; 135.0\left[\mathrm{C}_{6} \mathrm{H}\left(\mathrm{CH}_{3}\right)_{4}\right] ; 135.8[\mathrm{NCHN}] ; 136.4$ $\left[\mathrm{C}_{6} \mathrm{H}\left(\mathrm{CH}_{3}\right)_{4}\right]$.

Compound 12: N-(butyl)-N'-(2,3,4,5,6pentamethylbenzyl)imidazolium bromide

Yield: $89 \%$. m.p.: $117{ }^{\circ} \mathrm{C} .{ }^{1} \mathrm{H}-\mathrm{NMR}(\delta, 400 \mathrm{MHz}$, $\left.\mathrm{CDCl}_{3}\right): 0.86\left[\mathrm{t}, 3 \mathrm{H}, J=7.4 \mathrm{~Hz}, \mathrm{CH}_{3} \mathrm{CH}_{2} \mathrm{CH}_{2} \mathrm{CH}_{2} \mathrm{~N}\right]$; $1.29\left[\mathrm{~m}, 2 \mathrm{H}, \mathrm{CH}_{3} \mathrm{CH}_{2} \mathrm{CH}_{2} \mathrm{CH}_{2} \mathrm{~N}\right] ; 1.83[\mathrm{~m}, 2 \mathrm{H}$, $\left.\mathrm{CH}_{3} \mathrm{CH}_{2} \mathrm{CH}_{2} \mathrm{CH}_{2} \mathrm{~N}\right] ; 2.13\left[\mathrm{~s}, 6 \mathrm{H}, \mathrm{C}_{6}\left(\mathrm{CH}_{3}\right)_{5}-\mathrm{o}-\mathrm{CH}_{3}\right] ; 2.14$ $\left[\mathrm{s}, 6 \mathrm{H}, \mathrm{C}_{6}\left(\mathrm{CH}_{3}\right)_{5}-m-\mathrm{CH}_{3}\right] ; 2.17\left[\mathrm{~s}, 3 \mathrm{H}, \mathrm{C}_{6}\left(\mathrm{CH}_{3}\right)_{5}-p-\mathrm{CH}_{3}\right]$; $4.29\left[\mathrm{t}, 2 \mathrm{H}, J=7.2 \mathrm{~Hz}, \mathrm{CH}_{3} \mathrm{CH}_{2} \mathrm{CH}_{2} \mathrm{CH}_{2} \mathrm{~N}\right] ; 5.57[\mathrm{~s}, 2 \mathrm{H}$, $\left.\mathrm{NCH}_{2} \mathrm{C}_{6}\left(\mathrm{CH}_{3}\right)_{5}\right] ; 6.83[\mathrm{t}, 1 \mathrm{H}, J=1.7 \mathrm{~Hz}, \mathrm{NCHCHN}] ; 7.54$ $[\mathrm{t}, 1 \mathrm{H}, J=1.7 \mathrm{~Hz}, \mathrm{NCHC} H \mathrm{~N}] ; 10.14[\mathrm{~s}, 1 \mathrm{H}, \mathrm{NCHN}]$. ${ }^{13} \mathrm{C}-\mathrm{NMR}\left(\delta, 100 \mathrm{MHz}, \mathrm{CDCl}_{3}\right): 13.4\left[\mathrm{CH}_{3} \mathrm{CH}_{2} \mathrm{CH}_{2} \mathrm{CH}_{2} \mathrm{~N}\right]$; $16.8\left[\mathrm{CH}_{3} \mathrm{CH}_{2} \mathrm{CH}_{2} \mathrm{CH}_{2} \mathrm{~N}\right] ; 16.9\left[\mathrm{C}_{6}\left(\mathrm{CH}_{3}\right)_{5}-O-\mathrm{CH}_{3}\right]$; $17.2\left[\mathrm{C}_{6}\left(\mathrm{CH}_{3}\right)_{5}-m-\mathrm{CH}_{3}\right] ; 19.4\left[\mathrm{C}_{6}\left(\mathrm{CH}_{3}\right)_{5}-p-\mathrm{CH}_{3}\right] ; 32.1$ $\left[\mathrm{CH}_{3} \mathrm{CH}_{2} \mathrm{CH}_{2} \mathrm{CH}_{2} \mathrm{~N}\right] ; 49.0\left[\mathrm{CH}_{3} \mathrm{CH}_{2} \mathrm{CH}_{2} \mathrm{CH}_{2} \mathrm{~N}\right] ; 50.0$ $\left[\mathrm{NCH}_{2} \mathrm{C}_{6}\left(\mathrm{CH}_{3}\right)_{5}\right] ; 120.8[\mathrm{NCHCHN}] ; 122.2[\mathrm{NCHCHN}] ;$ $125.3\left[\mathrm{C}_{6}\left(\mathrm{CH}_{3}\right)_{5}\right] ; 133.5\left[\mathrm{C}_{6}\left(\mathrm{CH}_{3}\right)_{5}\right] ; 133.7\left[\mathrm{C}_{6}\left(\mathrm{CH}_{3}\right)_{5}\right]$; $136.4\left[\mathrm{C}_{6}\left(\mathrm{CH}_{3}\right)_{5}\right] ; 137.2[\mathrm{NCHN}]$.

\section{Synthesis of 13, 14}

These compounds were synthesized according to the literature method (Meyer, Taige, Strassner, 2009).

Compound 13: N-(1-methyl-2-oxopropyl)-N'-(2,3,5,6tetramethylbenzyl)imidazolium bromide

Yield: 79\%; m.p: $187{ }^{\circ} \mathrm{C} .{ }^{1} \mathrm{H}-\mathrm{NMR}(\delta, 400 \mathrm{MHz}$, $\left.\mathrm{CDCl}_{3}\right): 1.81\left[\mathrm{~d}, J=7.4 \mathrm{~Hz}, 3 \mathrm{H}, \mathrm{CH}_{3}\right] ; 2.10[\mathrm{~s}, 6 \mathrm{H}$, $\left.\mathrm{C}_{6} \mathrm{H}\left(\mathrm{CH}_{3}\right)_{4}-\mathrm{o}-\mathrm{CH}_{3}\right] ; 2.14\left[\mathrm{~s}, 6 \mathrm{H}, \mathrm{C}_{6} \mathrm{H}\left(\mathrm{CH}_{3}\right)_{4}-m-\mathrm{CH}_{3}\right]$; $3.68\left[\mathrm{~s}, 3 \mathrm{H}, \mathrm{OCH}_{3}\right] ; 5.57\left[\mathrm{~s}, 2 \mathrm{H}, \mathrm{NCH}_{2} \mathrm{C}_{6} \mathrm{H}\left(\mathrm{CH}_{3}\right)_{4}\right]$; $5.90[\mathrm{q}, J=6.9 \mathrm{~Hz}, 2 \mathrm{H}, \mathrm{CH}] ; 6.89$ [s, 1H, NCHCHN]; $6.95\left[\mathrm{~s}, 1 \mathrm{H}, \mathrm{C}_{6} H\left(\mathrm{CH}_{3}\right)_{4}\right] ; 7.69[\mathrm{~s}, 1 \mathrm{H}, \mathrm{NCHCHN}] ; 10.27$ $[\mathrm{s}, 1 \mathrm{H}, \mathrm{NCHN}] \cdot{ }^{13} \mathrm{C}-\mathrm{NMR}\left(\delta, 100 \mathrm{MHz}, \mathrm{CDCl}_{3}\right): 15.4$ $\left[\mathrm{NCH}_{2} \mathrm{C}_{6} \mathrm{H}\left(\mathrm{CH}_{3}\right)_{4}\right] ; 17.9\left[\mathrm{CH}_{3}\right] ; 20.1\left[\mathrm{NCH}_{2} \mathrm{C}_{6} \mathrm{H}\left(\mathrm{CH}_{3}\right)_{4}\right] ;$ $48.3[\mathrm{CH}] ; 53.2\left[\mathrm{NCH}_{2} \mathrm{C}_{6} \mathrm{H}\left(\mathrm{CH}_{3}\right)_{4}\right] ; 57.2\left[\mathrm{OCH}_{3}\right] ; 120.2$ $[\mathrm{NCHHN}] ; 121.4[\mathrm{NCHCHN}] ; 127.4\left[\mathrm{C}_{6} \mathrm{H}\left(\mathrm{CH}_{3}\right)_{4}\right] ; 133.2$ $\left[\mathrm{C}_{6} \mathrm{H}\left(\mathrm{CH}_{3}\right)_{4}\right] ; 133.7\left[\mathrm{C}_{6} \mathrm{H}\left(\mathrm{CH}_{3}\right)_{4}\right] ; 134.6\left[\mathrm{C}_{6} \mathrm{H}\left(\mathrm{CH}_{3}\right)_{4}\right]$; $136.6[\mathrm{NCHN}] ; 168.8(C=\mathrm{O})$.
Compound 14: N-(1-methyl-2-oxopropyl)-N'-

(2,3,4,5,6-pentamethylbenzyl)imidazolium bromide

Yield: $82 \%$; m.p.: $193{ }^{\circ} \mathrm{C} .{ }^{1} \mathrm{H}-\mathrm{NMR}(\delta, 400 \mathrm{MHz}$, $\left.\mathrm{CDCl}_{3}\right): 1.83\left[\mathrm{~d}, J=7.4 \mathrm{~Hz}, 3 \mathrm{H}, \mathrm{CH}_{3}\right] ; 2.14[\mathrm{~s}, 6 \mathrm{H}$, $\left.\mathrm{C}_{6}\left(\mathrm{CH}_{3}\right)_{5}-\mathrm{o}-\mathrm{CH}_{3}\right] ; 2.16\left[\mathrm{~s}, 6 \mathrm{H}, \mathrm{C}_{6}\left(\mathrm{CH}_{3}\right)_{5}-m-\mathrm{CH}_{3}\right] ; 2.18[\mathrm{~s}$, $\left.3 \mathrm{H}, \mathrm{C}_{6}\left(\mathrm{CH}_{3}\right)_{5}-p-\mathrm{CH}_{3}\right] ; 3.70\left[\mathrm{~s}, 3 \mathrm{H}, \mathrm{OCH}_{3}\right] ; 5.58[\mathrm{~s}, 2 \mathrm{H}$, $\left.\mathrm{NCH}_{2} \mathrm{C}_{6}\left(\mathrm{CH}_{3}\right)_{5}\right] ; 5.94[\mathrm{q}, J=7.2 \mathrm{~Hz}, 2 \mathrm{H}, \mathrm{CH}] ; 6.90[\mathrm{~s}, 1 \mathrm{H}$, $\mathrm{NCHCHN}] ; 7.67[\mathrm{~s}, 1 \mathrm{H}, \mathrm{NCHCHN}] ; 10.30[\mathrm{~s}, 1 \mathrm{H}, \mathrm{NCHN}]$. ${ }^{13} \mathrm{C}-\mathrm{NMR}\left(\delta, 100 \mathrm{MHz}, \mathrm{CDCl}_{3}\right): 17.0\left[\mathrm{NCH}_{2} \mathrm{C}_{6}\left(\mathrm{CH}_{3}\right)_{5}\right]$; $17.1\left[\mathrm{NCH}_{2} \mathrm{C}_{6}\left(\mathrm{CH}_{3}\right)_{5}\right] ; 17.4\left[\mathrm{NCH}_{2} \mathrm{C}_{6}\left(\mathrm{CH}_{3}\right)_{5}\right] ; 18.4\left[\mathrm{CH}_{3}\right]$; $49.5[\mathrm{CH}] ; 53.7\left[\mathrm{NCH}_{2} \mathrm{C}_{6}\left(\mathrm{CH}_{3}\right)_{5}\right] ; 57.8\left[\mathrm{OCH}_{3}\right] ; 120.9$ $[\mathrm{NCHHN}] ; 122.3[\mathrm{NCHCHN}] ; 125.4\left[\mathrm{C}_{6}\left(\mathrm{CH}_{3}\right)_{5}\right] ; 133.8$ $\left[C_{6}\left(\mathrm{CH}_{3}\right)_{5}\right] ; 134.0\left[\mathrm{C}_{6}\left(\mathrm{CH}_{3}\right)_{5}\right] ; 136.9\left[\mathrm{C}_{6}\left(\mathrm{CH}_{3}\right)_{5}\right] ; 137.5$ $[\mathrm{NCHN}] ; 169.4(C=\mathrm{O})$.

\section{Antimicrobial assays}

Antimicrobial activity was determined using the following microorganisms. The Gram-negative (Gr) were: Escherichia coli ATCC 35218, Salmonella typhimurium ATCC 14028, Proteus vulgaris ATCC 33420, Serratia marcescens ATCC 13880, Enterobacter aerogenes ATCC 13048, and the Gram-positive (Gr+) were: Micrococcus luteus ATCC 9341, Staphylococcus aureus ATCC 25923, Staphylococcus epidermidis ATCC 12228, Bacilllus cereus ATCC 11778, Bacilllus subtilis ATCC 6633, Bacillus thuringiensis, Enterococcus faecalis ATCC 29212, Streptococcus pneumoniae ATCC 27336 and Listeria monocytogenes ATCC 19112, and the yeasts were: Candida albicans ATCC 10231, Candida utilis ATCC 9950, Candida tropicalis, Candida glabrata and Saccharomyces cerevisiae ATCC 9763. Thirteen bacterial strains and three yeast strains were obtained from the American Type Culture Collection (ATCC, Rockville, MD, USA). Other strains were obtained from Faculty of Medicine, Adnan Menderes University.

Screenings for antimicrobial activities were carried out by the agar well diffusion method against test microorganisms (Collins et al., 2004; Clinical and Laboratory Standards Institute, 2015). Fresh stock solutions $\left(1000 \mu \mathrm{g} \mathrm{mL}^{-1}\right)$ of the compounds were prepared in DMSO according to the needed concentrations for the experiments. The inoculum suspensions of the tested bacteria and yeasts were prepared from the broth cultures $(18-24 \mathrm{~h})$ and the turbidity equivalent adjusted to 0.5 McFarland standard tubes to give a concentration of $1 \mathrm{x}$ $10^{8}$ bacterial cells and $1 \times 10^{6}$ yeast cells $/ \mathrm{mL}$. To test the antimicrobial activity of each unsymmetrically substituted imidazolium salts, Mueller Hinton Agar medium (25 mL) was poured into each petri plate and was inoculated with $0.1 \mathrm{~mL}$ broth culture of bacteria or yeasts. Then using 
sterile cork borer of $6 \mathrm{~mm}$ diameter, wells were bored into the seeded agar plates and were loaded with a $50 \mu \mathrm{L}$ volume of unsymmetrically substituted imidazolium salts.

Plates inoculated with E. coli ATCC 35218, S. typhimurium ATCC 14028, S. aureus ATCC 25923, $S$. epidermidis ATCC 12228, E. faecalis ATCC 29212, S. pneumoniae ATCC 27336, S. marcescens ATCC 13880, P. vulgaris ATCC 33420, L. monocytogenes ATCC 19112, and E. aerogenes ATCC 13048 were incubated at 37 ${ }^{\circ} \mathrm{C}$ for $24 \mathrm{~h}$ and those inoculated with $M$. luteus ATCC 9341, B. cereus ATCC 11778, B. subtilis ATCC 6633, B. thuringiensis, C. albicans ATCC 10231, C. utilis ATCC 9950 C. tropicalis, C. glabrata and S. cerevisiae ATCC 9763 were incubated at $30^{\circ} \mathrm{C}$ for $24 \mathrm{~h}$.

After incubation, the diameter of the inhibition zone was measured. Discs of Chloramphenicol (C30, Oxoid), Gentamycin (GN10 Oxoid), Tetracycline (TE30), Erytromycine (E15), Ampicillin (AMP10) and Nystatine (NS100) were used as positive controls.

The minimum inhibitory concentrations (MIC) were determined for antimicrobial activities by preparing a microdilution broth (Jones et al., 1985; Jorgensen, Ferraro, 2009; CLSI, 2009). All the bacteria were inoculated in the Nutrient Broth and incubated at $30-37{ }^{\circ} \mathrm{C}$ for $24 \mathrm{~h}$ while the yeasts were inoculated in Malt Extract Broth and incubated at $30{ }^{\circ} \mathrm{C}$ for $48 \mathrm{~h}$. The compounds were dissolved in DMSO $\left(2 \mathrm{mg} \mathrm{mL}^{-1}\right)$. From the stock solution, two fold serial dilutions of the compounds were employed to determine the MIC ranging from 256 to $0.125 \mu \mathrm{g} \mathrm{mL}^{-1}$. The lowest concentration of antimicrobial agent that resulted in complete inhibition of the microorganisms was represented as MIC $(\mu \mathrm{g} \mathrm{mL}$ $\left.{ }^{1}\right)$. As positive controls, Streptomycin (I.E. Ulagay) for bacteria and Nystatine (NS100, Oxoid) for yeast were used in the dilution method.

\section{RESULTS AND DISCUSSION}

Imidazole has been easily converted into IMSs by attachment of a wide variety of functional groups onto positions 1 and 3 of the imidazole ring. The target salts (114) shown in Figure 1 have been obtained by quaternization of 1-substituted imidazole by variously substituted benzyl halides. The IMSs were obtained as solids, which have been observed to be air stable, except compound 9, and soluble in chlorinated solvents and alcohol. The salts could be purified by recrystallization from ethanol or $\mathrm{CH}_{2} \mathrm{Cl}_{2}$ (DCM) and by addition of $\mathrm{Et}_{2} \mathrm{O}$. The IMSs were identified by NMR spectroscopy. ${ }^{1} \mathrm{H}-\mathrm{NMR}$ chemical shifts were consistent with the proposed structures; the resonances for $\mathrm{NCHN}$ protons were observed as a sharp singlet between $\delta 9.47$ and 10.39 ppm. ${ }^{13} \mathrm{C}$-NMR of these salts showed the $\mathrm{C} 2$ carbon between $\delta 136.4$ and 141.3 ppm. The representative ${ }^{1} \mathrm{H}$ - and ${ }^{13} \mathrm{C}-\mathrm{NMR}$ spectra of the compounds 1, 2, 3, 6, 11 were given as Supplementary Data (Figure 1-10).

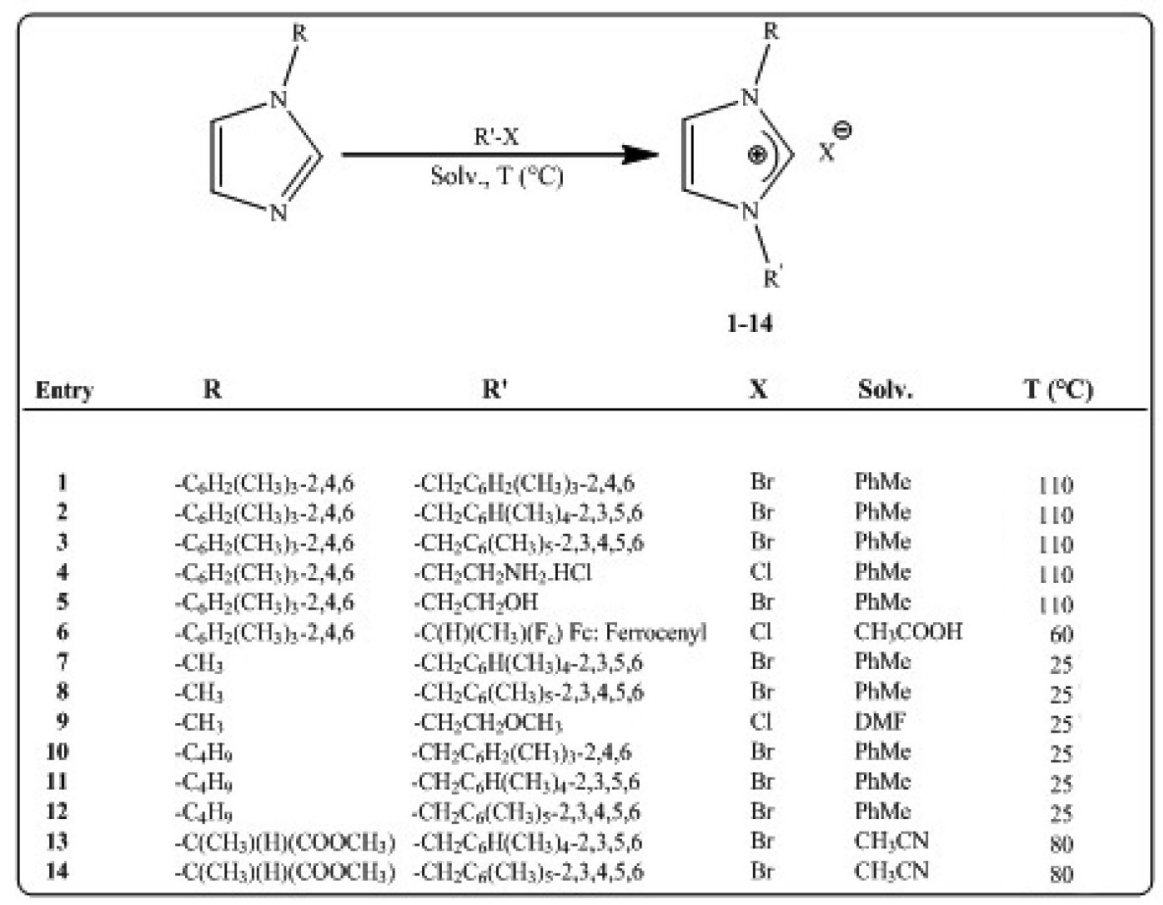

FIGURE 1- Synthesis and formula of the imidazolium salts (1-14) used for antimicrobial activity. 
All of the compounds used in this study were tested for their in vitro antimicrobial activity by the agar well diffusion method. After then compounds showing antimicrobial activity were examined by MIC. Inhibition zones $(\mathrm{mm})$ of the compounds were listed in Table I. In addition, the assay, were compared with knowing reference antibiotic and antifungal reagents. MIC values forming inhibition zone $(\mathrm{mm})$ of the compounds were listed in Table II.

Compounds 1, 2, 3 and $\mathbf{6}$ demonstrated stronger activity against $M$. luteus, ATCC 9341, S. aureus ATCC 25923, S. epidermidis ATCC 12228, B. cereus ATCC 11778, B. subtilis ATCC 6633 and C. tropicalis. The other compounds had effect as follows: compounds 1 and 2; 18-20 mm against $S$. aureus ATCC 25923 and $S$. epidermidis ATCC 12228 (Figure 2a), compounds 1 and 3; 14-18 mm against $M$. luteus ATCC 9341 (Figure 2b), compound 1; 15-18 mm against $B$. cereus ATCC 11778 and B. subtilis ATCC 6633 (Figure 3a, 3b) compound 6;15 $\mathrm{mm}$ against $C$. tropicalis. In addition, compounds $\mathbf{1}$, $\mathbf{2}$ and $\mathbf{3}$ showed effects slightly against $L$. monocytogenes

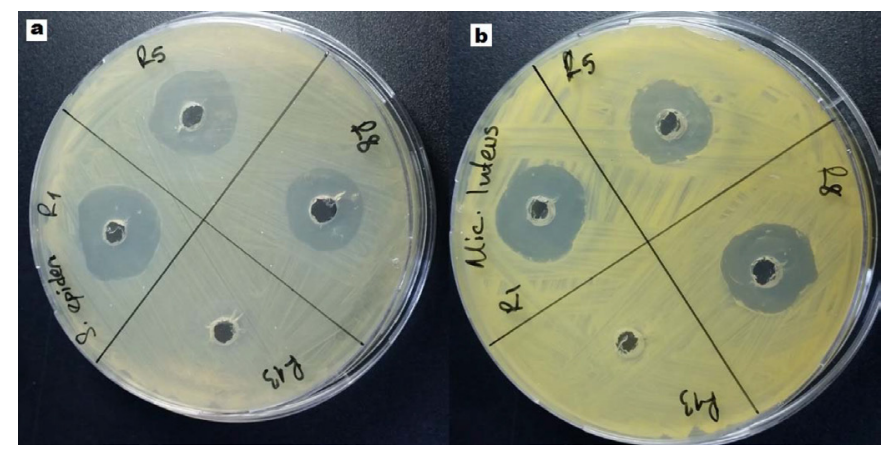

FIGURE 2 - a - Effects of compounds 1 (R1), 2 (R5), 3 (R8), 11(R13) against Stapylococcus epidermidis ATCC 12228. b Effects of compounds 1 (R1), 2 (R5), 3 (R8), 11(R13) against Micrococcus luteus ATCC 9341.

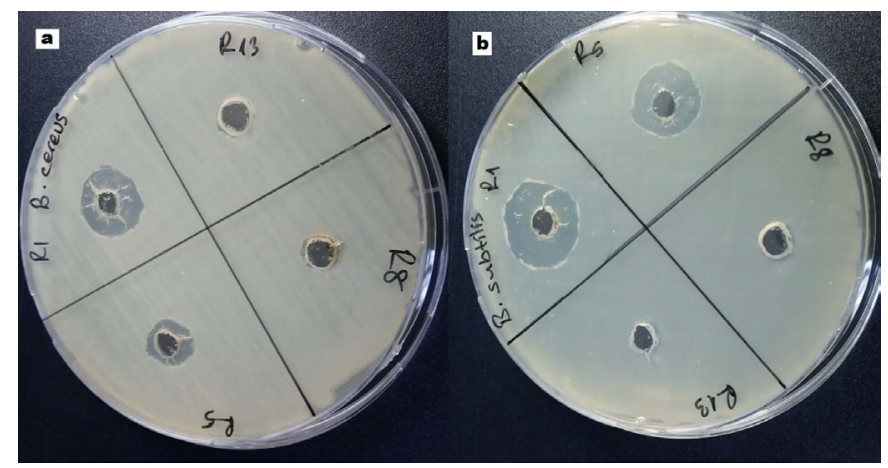

FIGURE 3- a - Effects of compounds 1 (R1), 2 (R5), 3 (R8), 11(R13) against Bacillus cereus ATCC 11778. b - Effects of compounds 1 (R1), 2 (R5), 3 (R8), 11(R13) against Bacillus subtilis ATCC 6633.
ATCC 19112, M. luteus, ATCC 9341 and S. aureus ATCC 25923, respectively.

However, 1, $\mathbf{2}$ and $\mathbf{1 1}$ showed the lowest effects against $B$. thrungiensis, $B$. cereus ATCC 11778 and $S$. epidermidis ATCC 12228, respectively. For example, compound 1, 2 and $\mathbf{1 1}$ had effect $10 \mathrm{~mm} \mathrm{~B}$. thrungiensis, $8 \mathrm{~mm} \mathrm{~B}$. cereus ATCC 11778 and $9 \mathrm{~mm}$ S. epidermidis ATCC 12228, respectively On the other hand, 4, 5, 7, 8, 9, $10,12,13$ and 14 had no effect on the test microorganisms examined (Table I).

MIC values in Table II have also showed that some of the compounds tested presented noteworthy antimicrobial activity on the tested microorganisms. Compounds 1, 2 and $\mathbf{3}$ have revealed a strong activity against some bacterial cultures such as M. luteus ATCC 9341 (compound $1=16 \mu \mathrm{g} \mathrm{mL}^{-1}, 2=64 \mu \mathrm{g} \mathrm{mL}^{-1}, 3=32 \mu \mathrm{g}$ $\mathrm{mL}^{-1}$ ), S. aureus ATCC 25923, (compound $1=8 \mu \mathrm{g} \mathrm{mL}^{-1}$, $2=16 \mu \mathrm{g} \mathrm{mL}^{-1}$ ), S. epidermidis ATCC 12228 (compound $\left.1=8 \mu \mathrm{g} \mathrm{mL}^{-1}, 2=16 \mu \mathrm{g} \mathrm{mL}^{-1}, 3=32 \mu \mathrm{g} \mathrm{mL}^{-1}\right)$, B. subtilis ATCC $6633\left(1=16 \mu \mathrm{g} \mathrm{mL}^{-1}\right)$, B. cereus ATCC $11778(1=$ $32 \mu \mathrm{g} \mathrm{mL} \mathrm{m}^{-1}$ ), L. monocytogenes ATCC 19112 (compound $1=64 \mu \mathrm{g} \mathrm{mL}^{-1}$ ), C. tropicalis (compound $6=32 \mu \mathrm{g} \mathrm{mL}^{-1}$ ). However, compounds 1, 2, 3 and 11 have displayed lower effect against Bacillus thrungiensis (compound $1=128 \mu \mathrm{g}$ $\mathrm{mL}^{-1}, 2=256 \mu \mathrm{g} \mathrm{mL}^{-1}$ ), S. aureus ATCC 25923 (compound $3=128 \mu \mathrm{g} \mathrm{mL}^{-1}$ ), S. epidermidis ATCC 12228 (compound $\left.11=256 \mu \mathrm{g} \mathrm{mL}^{-1}\right)$.

Micrococcus luteus does not regard as a pathogen bacteria but it can cause skin infections in individual with a decreased immune system such as new-born infants or patients with AIDS. The skin infections or chronic cutaneous infections result in pruritic eruptions of the skin in some areas as well as scattered papule lesions with or without central ulcerations (Smith et al., 1999). Recently, this organism was recognized as an opportunistic pathogen and has been implicated in recurrent bacteraemia, septic shock, septic arthritis, endocarditis, meningitis, intracranial suppuration, and cavitating pneumonia in immunosuppressed patients (Greenblatt et al., 2004).

Staphylococcus epidermidis generates biofilms to grow on plastic devices placed within the body (Costerton, Stewart, Greenberg, 2009). This happens most commonly on intravenous catheters and medical prostheses (Hedin, 1993). Infection can also appear in dialysis patients or anyone with an implanted plastic device that may have been contaminated. It also causes endocarditis, most often in patients with defective heart valves. In some other cases, sepsis can occur in hospital patients. The spread of the infection has been shown reduced with the hand washing (Otto, 2009). 
TABLE II - Antimicrobial activities of compounds as determined by MIC values $\left(\mu \mathrm{g} \mathrm{mL} \mathrm{L}^{-1}\right)$

\begin{tabular}{lccccccc}
\hline Test microorganisms & $\mathbf{1}$ & $\mathbf{2}$ & $\mathbf{3}$ & $\mathbf{6}$ & $\mathbf{1 1}$ & Str & NS 100 \\
\hline Micrococcus luteus ATCC 9341 & 16 & 64 & 32 & - & - & 32 & NT \\
Stapylococcus aureus ATCC 25923 & 8 & 16 & 128 & - & - & 32 & NT \\
Stapylococcus epidermidis ATCC 12228 & 8 & 16 & 32 & - & 256 & 64 & NT \\
Bacilllus cereus ATCC 11778 & 16 & - & - & - & - & 64 & NT \\
Bacillus subtilis ATCC 6633 & 32 & - & - & - & - & 64 & NT \\
Bacillus thrungiensis* & 128 & 256 & - & - & - & 64 & NT \\
Listeria monocytogenes ATCC 19112 & 64 & - & - & - & - & 64 & NT \\
Candida tropicalis* & - & - & - & 32 & - & NT & 64 \\
\hline
\end{tabular}

1: N-(2,4,6-trimethylphenyl)-N'-(2,4,6-trimethylbenzyl)imidazolium bromide, 2: N-(2,4,6-trimethylphenyl)-N'-(2,3,5,6tetramethylbenzyl)imidazolium bromide, 3: N-(2,4,6-trimethylphenyl)-N'-(2,3,4,5,6-pentamethylbenzyl)imidazolium bromide, 6: N-(ferrocenylethyl)-N'-(2,4,6-trimethylphenyl)imidazolium chloride, 11: N-(butyl)-N'-(2,3,5,6-tetramethylbenzyl)imidazolium bromide. Compounds 4, 5, 7, 8, 9, 10,12, 13 and 14 did not show antimicrobial activity. Str = Streptomycin, NS 100= Nystatine. (-): Not tested. * From the Faculty of Medicine, Adnan Menderes University.

TABLE I - Antimicrobial activities of unsymmetrically substituted imidazolium salts (1000 $\left.\mu \mathrm{g} \mathrm{mL}^{-1}\right)$ (Inhibition zone mm)

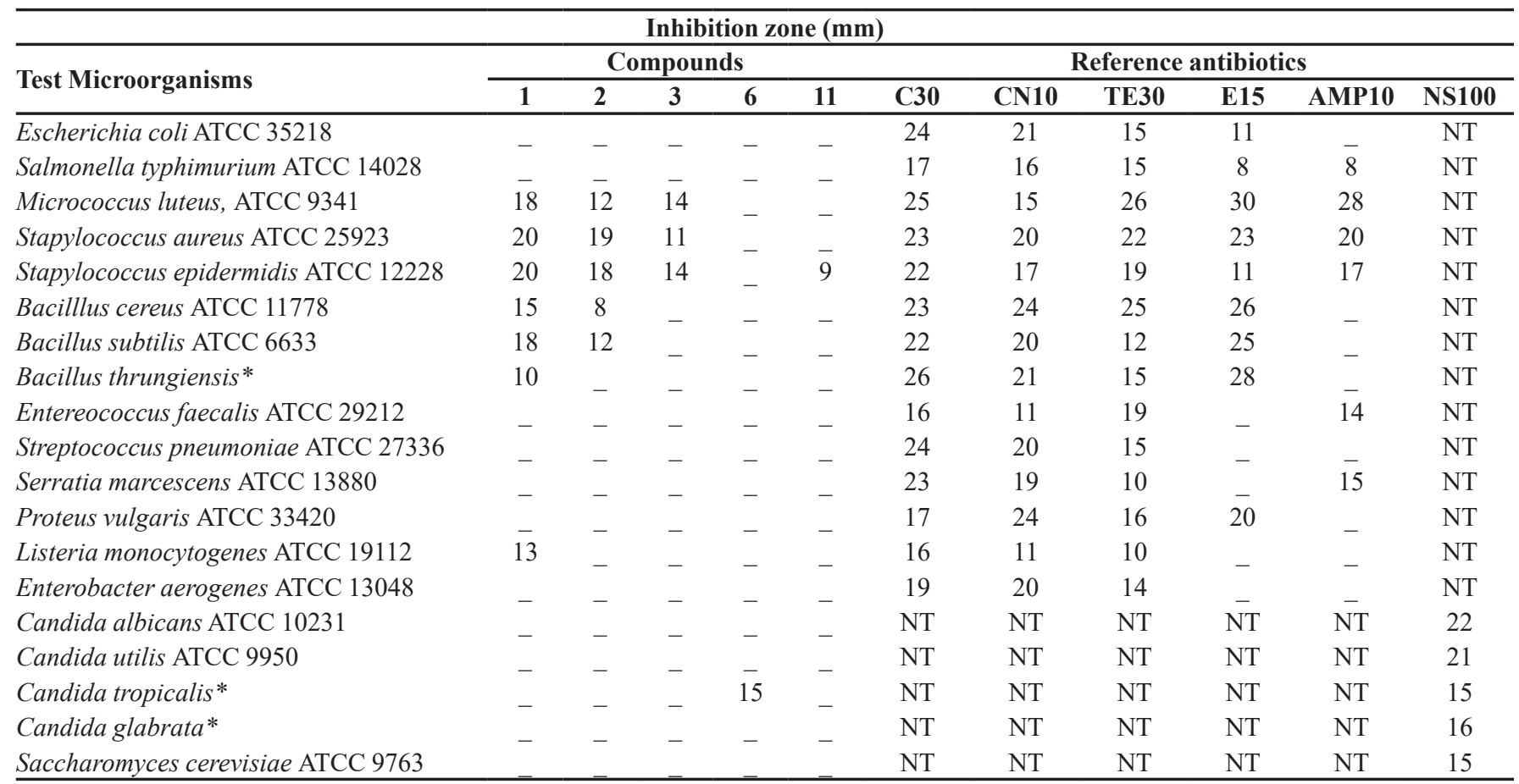

(-): Zone did not occur. NT: Not tested; Compounds 4, 5, 7, 8, 9, 10, 12, 13 and 14 showed no antimicrobial activity. ${ }^{*}$ Special gift from the Faculty of Medicine, Adnan Menderes University. 1: $N$-(2,4,6-trimethylphenyl)- $N$ '-(2,4,6-trimethylbenzyl)imidazolium bromide, 2 : $N$-(2,4,6trimethylphenyl)- $N^{\prime}$-(2,3,5,6-tetramethylbenzyl)imidazolium bromide, 3: $N$-(2,4,6-trimethylphenyl)- $N^{\prime}$-(2,3,4,5,6-pentamethylbenzyl) imidazolium bromide, 4: $N$-(2,4,6-trimethylphenyl)- $N^{\prime}$-(hydroxyethyl)imidazolium bromide, 5: $N$-(2,4,6-trimethylphenyl)- $N^{\prime}$-(ethylamine) imidazolium chloride hydrochloride, 6: $N$-(ferrocenylethyl)- $N^{\prime}$-(2,4,6-trimethylphenyl)imidazolium chloride, 7: $N$-(methyl)- $N^{\prime}$-(2,3,5,6tetramethylbenzyl)imidazolium bromide, $8: N$-(methyl)- $N$ '-(2,3,4,5,6-pentamethylbenzyl)imidazolium bromide, 9: $N$-(methyl)- $N$ '-(2methoxyethyl)imidazolium chloride, 10 : $N$-(butyl)- $N^{\prime}$-(2,4,6-trimethylbenzyl)imidazolium bromide, 11: $N$-(butyl)- $N$ '-(2,3,5,6-tetramethylbenzyl) imidazolium bromide, 12: $N$-(butyl)- $N^{\prime}$-(2,3,4,5,6-pentamethylbenzyl)imidazolium bromide, 13: $N$-(1-methyl-2-oxopropyl)- $N$ '-(2,3,5,6tetramethylbenzyl)imidazolium bromide, 14: $N$-(1-methyl-2-oxopropyl)- $N$ '-(2,3,4,5,6-pentamethylbenzyl)imidazolium bromide. C30: Chloramphenicol (30 mg Oxoid); CN10: Gentamycin (10 mg, Oxoid); TE30: Tetracycline (30 mg, Oxoid); E15: Erytromycin (15 mg, Oxoid); AMP10: Ampicillin (10 mg, Oxoid); NS: Nystatine (100 mg, Oxoid). 
Members of the genus Bacillus are aerobic spore forming rods which are ubiquitous in nature (Tuazon, 2000). Despite their widespread distribution, even as a normal skin flora, Bacillus spp. rarely causes infections. The exception is Bacillus cereus, which is a wellknown cause of food poisoning and a dreaded cause of posttraumatic endophthalmitis (Tuazon, 2000). B. cereus can also cause opportunistic infections, mainly in the immunocompromised host (Tuazon, 2000; Drobniewski, 1993). Besides, B. subtilis is only known as a cause of disease in severely immunocompromised patients and it rarely causes food poisoning. (Oggioni et al., 1998; Ryan, Ray, 2004).

Listeria monocytogenes is the bacterium that causes the infection listeriosis. This bacterium results in septicemia, meningitis, encephalitis, corneal ulser, pneumonia (Armstrong, Fung, 1993).

Candida tropicalis has emerged as a potentially dangerous opportunistic fungus. This may be due to an increased awareness and specific identification of $C$. tropicalis as an etiologic agent of infection and an increase in the number of compromised patients susceptible to opportunistic fungi (Horn et al., 1985). C. tropicalis also causes variety of infections including pyelonephritis (Seidenfeld et al., 1982) lower urinary tract infections, thrombophlebitis, arthritis, bursitis, meningitis, multiple organ infection, pericarditis and candidia vulvovaginitis (Seidenfeld et al., 1982; Finberg et al., 2004).

As a result, imidazolium salts containing ferrocene (compound 6) were determined to be inactive against microorganisms, ii) binding of the alkyl group instead of the aryl group (compounds $\mathbf{2}$ and $\mathbf{3}$ ), except $\mathbf{1}$ and $\mathbf{1 1}$, to one of the nitrogen atoms of the imidazole ring decreased the activity against microorganisms, iii) a decrease were identified in activity against microorganisms with increasing steric hindrance.

\section{CONCLUSION}

In summary, we have investigated antimicrobial activity of some $N$-substituted imidazolium salts (114). The compounds were characterized by NMR spectroscopy ( ${ }^{1} \mathrm{H}$ - and ${ }^{13} \mathrm{C}$-NMR). Compounds $\mathbf{1}$ and 2 were found that the methyl bearing benzyl group as substituent on imidazolium ring had the specific activity against Gram-positive bacteria. Remarkable activity was found in compound $\mathbf{2}$ carrying a methyl bearing benzyl substituent on the imidazolium ring. MICof the most active derivatives ( $\mathbf{1}$ and $\mathbf{2}$ ) were shown to be as low as 8 $\mu \mathrm{g} / \mathrm{mL}$ against $S$. aureus ATCC 25923 and $S$. epidermidis ATCC 12228 , and $16 \mu \mathrm{g} / \mathrm{mL}$ against $S$. aureus ATCC
25923 and S. epidermidis ATCC 12228. Only one of the compounds synthesized (6) was effective against yeast $(C$. trophicalis). It is worthy to mention that the introduction of the alkylated benzyl group to the nitrogen atom on the imidazolium ring increased MIC values.

\section{ACKNOWLEDGMENTS}

This work was supported by the TUBITAK (Project No: 110T765).

\section{REFERENCES}

ARMSTRONG, R.W.; FUNG P.C. Brainstem encephalitis (rhombencephalitis) due to Listeria monocytogenes: case report and review. Clin. Infect. Dis., v.16, p.689-702, 1993.

CLINICALAND LABORATORY STANDARDS INSTITUTE. M07-A8: Methods for dilution antimicrobial susceptibility testing for bacteria that grow aerobically: approved standard. 8.ed. Wayne: CLSI, 2009. p.1-65.

CLINICALAND LABORATORY STANDARDS INSTITUTE. CLSI. M02-A12: performance standards for antimicrobial disk susceptibility tests: approved standard. 12.ed. Wayne: CLSI, 2015. p.1-73.

COLLINS, C.H.; LYNE, P.M.; GRANGE, J.M.; FALKINHAM, J.O. Collins and Lyne's microbiological methods. 8.ed. London: Butterworths, 2004. 456p.

COSTERTON, J.W.; STEWART, P.S.; GREENBERG, E.P. Bacterial biofilms: a common cause of persistent infections. Science, v.284, n.5418, p.1318-1322, 1999.

DEMBERELNYMBA, D.; KIM, K.S.; CHOI, S.; PARK, S.Y.; LEE, H.; KIM, C.J.; YOO, I.D. Synthesis and antimicrobial properties of imidazolium and pyrrolidinonium salts. Bioorg Med. Chem., v.12, p.853-857, 2004.

DOMINIANNI, S.J.; YEN, T.T. Oral hypoglycemic agents. discovery and structure activity elationships of phenacylimidazolium halides. J. Med. Chem., v.32, p.23012306, 1989.

DROBNIEWSKI, F.A. Bacillus cereus and related species. Clin. Microbiol. Rev., v.6, p.324-338, 1993. 
ELSHAARAWY, R.F.M.; KHEIRALLA, Z.H.; RUSHDY,A.A.; JANIAK, C. New water soluble bis-imidazolium salts with a saldach scaffold: synthesis, characterization and in vitro cytotoxicity/bactericidal studies. Inorg. Chim. Acta, v.421, p.110-122, 2014.

FINBERG, R.W.; MOELLERING, R.C.; TALLY, F.P.; CRAIG, W.A.; PANKEY, G.A., DELLINGER, E.P.; WEST, M.A.; JOSHI, M.; LINDEN, P.K.; ROLSTON, K.V.; ROTSCHAFER, J.C.; RYBAK, M.J. The importance of bactericidal drugs: future directions in infectious disease. Clin. Infect. Dis., v.39, p.1314-1320, 2004.

GENÇAY, G. Synthesis of unsymmetrical N-Heterocyclic carbene complexes and their catalytic properties. Aydin, 2013. 95p. M. Sc. Thesis - Adnan Menderes University Graduate School of Natural Sciences.

GREENBLATT, C.L.; BAUM, J.; KLEIN, B.Y.; NACHSHON, S.; KOLTUNOV, V.; CANO, R.J. Micrococcus luteus -- survival in amber. Microb Ecol., v.48, p.120-127, 2004.

GÜNAY, M.E.; GÜMÜŞADA, R.; ÖZDEMIR, N.; DINÇER, M.; ÇETINKAYA, B. Synthesis, X-ray structures, and catalytic activities of $\left(\kappa^{2}-\mathrm{C}, \mathrm{N}\right)$-palladacycles bearing imidazol-2-ylidenes. J. Organomet. Chem., v.694, p.23432349, 2009.

GÜNAY, M.E.; ÇOĞAŞLIOĞLU, G.G.; FIRINCI, R. The synthesis, characterization, and catalytic properties of $\left(\kappa^{2}-C, N\right)$-palladacycles with $N$-heterocyclic carbene-based ancillary ligands. Turk. J. Chem. v.39, p.1310-1316, 2015.

GÜNAY, M.E.; ÇOĞAŞLIOĞLU, G.G. The role of $N$-heterocyclic carbene substituents on ruthenium(II) complexes in the catalytic transfer hydrogenation of acetophenone. Turk. J. Chem. v.40, p.296-304, 2016.

HEDIN, G. Staphylococcus epidermidis - hospital epidemiology and the detection of methicillin resistance, Scand. J. Infect. Dis. Suppl., v.90, p.1-59, 1993.

HORN, R., WONG, B., KIEHN, T.E.,ARMSTRONG, D. Fungemia in a cancer hospital: changing frequency, earlier onset, and results of therapy. Rev. Infect. Dis., v.7, p.646-655, 1985.

JAOUEN, G. Bioorganometallics: biomolecules, labeling, medicine. Weinheim: Wiley-VCH Verlag GmbH\&Co KGaA, 2006.
JONES, R.N.; BARRY, A.L.; GAVAN, T.L.; WASHINGTON, J.A. Susceptibility tests: microdilution and macrodilution broth procedures. In: LENNETTE, E.H.; BALOWS, A.; HAUSLER JR., W.J.; SHADOMY, H.J. (Eds.). Manual of clinical microbiology. 4.ed. Washington: American Society for Microbiology, 1985. p.972-977.

JORGENSEN, J.H.; FERRARO, M.J. Antimicrobial susceptibility testing: a review of general principles and contemporary practices. Med. Microbiol., v.49, p.1749$1755,2009$.

MEYER, A.; TAIGE, M.A.; STRASSNER, T. Chiral bisimidazolium salts derived from amino acids and their palladium(II)-and platinum(II)-biscarbene complexes. $J$. Organomet. Chem., v.694, p.1861-1868, 2009.

NAVARRO, J.A.R.; LIPPERT, B. Simple 1:1 and 1:2 complexes of metal ions with heterocycles as building blocks for discrete molecular as well as polymeric assemblies. Coord. Chem. Rev., v.222, p.219-250, 2001.

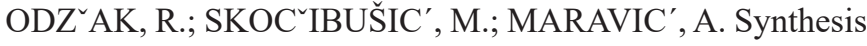
and antimicrobial profile of $\mathrm{N}$-substituted imidazolium oximes and their monoquaternary salts against multidrug resistant bacteria. Bioorg. Med. Chem., v.21, p.7499-7506, 2013.

OGGIONI, M.R.; POZZI, G.; VALENSIN, P.E.; GALIENI, P.; BIGAZZI, C. Recurrent septicemia in an immunocompromised patient due to probiotic strains of Bacillus subtilis. J. Clin. Microbiol., v.36, p.325-326, 1998.

OTTO, M. Staphylococcus epidermidis - the 'accidental' pathogen". Nat. Rev. Microbiol., v.7, p.555-567, 2009.

REINHARDT, A.; HORN, M.; PIEPER, S.J.; BROHL, A.; GIERNOTH, R.; OELKRUG, C.A.; NEUNDORF, I. Novel imidazolium salt-peptide conjugates and their antimicrobial activity. Bioconjugate Chem., v.25, p.2166-2174, 2014.

RIDUAN, S.N.; ZHANG, Y. Imidazolium salts and their polymeric materials for biological applications. Chem. Soc. Rev., v.42, p.9055-9070, 2013.

RYAN, K.J.; RAY, C.G., eds. Sherris medical microbiology: an introduction to infectious diseases. 4.ed. New York: McGraw Hill, 2004. 979p. 
SEO, H.; KIM, B.Y.; LEE, J.H.; PARK, H.J.; SON, S.U.; CHUNG, Y.K. Synthesis of chiral ferrocenyl imidazolium salts and their rhodium(I) and iridium(I) complexes. Organometallics, v.22, p.4783-4791, 2003.

SEIDENFELD, S.M.; LEMAISTRE, C.F.; SETIAWAN, H.; MUNFORD, R.S. Emphysematous pyelonephritis caused by Candida tropicalis. J. Infect. Dis., v.146, p.569, 1982.

SMITH, K.J.; NEAFIE, R.; YEAGER, J.; SKELTON, H.G. Micrococcus folliculitis in HIV-1 disease. Br. J. Dermatol., v.141, p.558-561, 1999.

TUAZON, C.U. Other Bacillus species. In: MANDELL, G.L.; BENNETTE, J.E.; DOLİN, R., eds. Mandel, Douglas and Bennette's principles and practice of infectious diseases. 5.ed. Philadelphia: Churchill Livingston, 2000. p.22202226.
VAN DER MADE, A.W.; VAN DER MADE, R.H. A convenient procedure for bromomethylation of aromatic compounds. Selective mono-, bis-, or trisbromomethylation. J. Org. Chem., v.58, p.1262-1263, 1993.

YENISARI, B. The synthesis of ferrocenyl imidazolium salts and their metal complexes. Aydın, 2014. M. Sc. Thesis Adnan Menderes University Graduate School of Natural Sciences.

ZENG, X.; YANG, X.; ZHANG, Y.; QING, C.; ZHANG, H. Synthesis and antitumor activity of 1-mesityl-3-(2naphthoylmethano)-1H-imidazolium bromide. Bioorg. Med. Chem. Lett., v.20, p.1844-1847, 2010.

Received for publication on $05^{\text {th }}$ March 2015 Accepted for publication on $21^{\text {st }}$ October 2016 